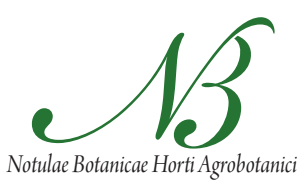

Cluj-Napoca

\title{
Relationships between Grain Yield and Yield Components in Bread Wheat under Different Water Availability (Dryland and Supplemental Irrigation Conditions)
}

\author{
Mohtasham MOHAMMADI I*, Peyman SHARIFI², Rahmatollah \\ KARIMIZADEH ${ }^{1}$, Mohammad Kazem SHEFAZADEH $^{3}$ \\ ${ }^{1}$ Dryland Agriculture Research Institute, Gachsaran Station, P.O. Box 178, Iran; mohtashammohammadi@yahoo.com ("corresponding author) \\ ${ }^{2}$ Islamic Azad University, Department of Agronomy and Plant Breeding, Rasht Branch, Rasht, Iran \\ ${ }^{3}$ Islamic Azad University, Department of Agronomy, Yasooj branch, Yasooj, Iran
}

\begin{abstract}
Path and correlation analysis were executed to investigate the relationships between grain yield and other important yield components in bread wheat (Triticum aestivum L.) genotypes during two years (2009-2011) under supplemental irrigation and dryland conditions. Field experiments were performed in a randomized complete block design with four replications. Grain yield showed positive correlation with plant height and test weight under supplemental irrigation condition. The similar results were also revealed between grain yield and plant height, spike length, days to maturity, agronomic score and test weight in dryland environment. The grain yield of bread wheat in dryland condition depended on the effect of plant height, days to maturity, agronomic score and 1000 kernel weight, whereas in supplemental irrigation was mainly related to plant height, spike length, 1000 kernel weight and test weight. The influence of 1000 kernel weight on grain yield in both environments seems to cause from the fact that grain yield in wheat is frequently the sink limited, and for this reason, the 1000 kernel weight has been reported as a promising trait for increasing grain yield in wheat under different conditions. The nearly equal value of correlation and path coefficients of plant height and grain yield showed plant height had positive and direct effect on grain yield, in both conditions and suggesting a criteria trait for improving of grain yield. The results showed that genotype 12 (CS/TH.SC//3*PVN/3/MIRLO/BUC/4/MILAN/5/ TILHI) is a high yielding potential genotype in moisture limited conditions.
\end{abstract}

Keywords: drought, path analysis, stepwise regression, supplemental irrigation, yield

\section{Introduction}

Bread wheat (Triticum aestivum L.) is an important food crop, which its harvested area and production is unfavorably affected by drought in major parts of the world. In most cases, yield is the target of the breeding program and "the great integrator" of genetics and environment. The final expression of yield under drought stress is a complex integration of constitutive plant traits and stress-responsive processes which depend on stress intensity, duration and timing with respect to growth stage. The measurement of yield components may provide additional insight into the expression of drought resistance in terms of productivity (Blum, 2011). The tolerance of crops to drought is the ability to growth and production under water deficit conditions. Severe water deficit can lead to dying or decrease of crop yield. However due to water deficit in most arid regions, crop plants resistance against drought has always been of great importance and has taken into account as one of the breeding factors (Khayatneghad et al., 2010). Irrigation could increase crop yield (Zhou and Chen, 2011), while it decreased water use efficiency (Zhou et al., 2011).
Correlation and path analysis could be help to introduce better traits for grain yield and determine the best parents for breeding programs.

Some of researchers indicated that the positive correlation between grain yield and yield component traits in wheat such as harvest index (Ghaderi et al., 2009), biological yield (Ghaderi et al., 2009; Kandic et al., 2009), number of spike per square meter (Leilah and Al-Khateeb, 2005), plant height (Leilah and Al-Khateeb, 2005), grains per spike (Khan et al., 2010) and 1000 kernel weight (Leilah and Al-Khateeb, 2005).

Selections based on simple correlation coefficients without regarding to interactions among yield and yield components may mislead the breeders to reach their main breeding purposes (Garci'a del Moral et al., 2003). Path coefficient analysis measures the inter-association among yield components for their direct and indirect effects on grain yield (Singh and Chaudhary, 1979). The investigation of direct and indirect effects of various characters on yield has major importance to increase the yielding capacity of bread wheat. 
196

Path analysis procedure was used by number of researchers in wheat. Mollasadeghi et al. (2011) indicated that number of grain per spike, grain weight, 1000 kernel weight and biological yield had the most direct and positive effect on grain yield. Shamsi et al. (2011) showed that the most important yield component on grain yield is number of grains per spike followed by number of spikes per unit area and 1000 kernel weight. Zakizadeh et al. (2010) revealed that the biological yield, grain weights per spike and number of spikes per . Nonetheless, had highest direct effects on grain yield. Leilah and Al-Khateeb (2005) showed that biological yield and harvest index had high positive direct effects on grain yield per area and the highest indirect effects were observed with weight of grains per spike, number of spikes per $\mathrm{m}^{2}$ and 100-grain weight. Taheri et al. (2011) indicated a positive and significant correlation between stress tolerance index with grain yield, biomass and harvest index under normal conditions. In stress conditions, there was a positive and significant correlation between stress tolerance index and awn length, spike length and plant height. Their results of path analysis indicated in all of moisture conditions, the biggest direct effect on stress tolerance index was related to grain yield. Kandic et al. (2009) indicated early vigor, early maturity and leaf senescence were found to be suitable for wheat breeding under different moisture regimes.

The main objectives of this research are determining direct and indirect effects of some morphological and yield components traits on grain yield and estimating correlation coefficients between grain yield and the other studied traits in bread wheat genotypes.

\section{Materials and methods}

\section{Field experiments}

Eighteen bread wheat genotypes (Tab. 1) were grown under two environments viz, stressed (dryland) and mid-

Tab. 1. Parentage and origin of studied genotypes

\begin{tabular}{|c|c|c|}
\hline Gen. no. & Genotype name & Origin \\
\hline 1 & BHRIKUTINL623-0NPL & CIMMYT \\
\hline 2 & TOBA97/PASTOR & CIMMYT \\
\hline 3 & KAUZ/PASTOR//BAV92/RAYON & CIMMYT \\
\hline 4 & CROC_1/AE.SQUARROSA (224)//OPATA/3/ BJY/COC//PRL/BOW & CIMMYT \\
\hline 5 & CHIR1/BABAX//JARU & CIMMYT \\
\hline 6 & FRTL $/ 2 *$ PIFED & CIMMYT \\
\hline 7 & CN079//PF70354/MUS/3/PASTOR/4/BABAX & CIMMYT \\
\hline 8 & PASTOR/ATTILA/3/DUCULA//VEE/MYNA & CIMMYT \\
\hline 9 & HXL7573/2*BAU//PASTOR/3/PASTOR & CIMMYT \\
\hline 10 & SKAUZ/BAV92//PASTOR & CIMMYT \\
\hline 11 & CS/TH.SC//3*PVN/3/MIRLO/BUC/4/MILAN/5/TILHI & CIMMYT \\
\hline 12 & CS/TH.SC//3*PVN/3/MIRLO/BUC/4/MILAN/5/TILHI & CIMMYT \\
\hline 13 & $\mathrm{CAL} / \mathrm{NH} / / \mathrm{H} 567.71 / 3 / \mathrm{SERI} / 4 / \mathrm{CAL} / \mathrm{NH} / / \mathrm{H} 567.71 / 5 / 2^{*} \mathrm{KAUZ} / 6 / \mathrm{PASTOR}$ & CIMMYT \\
\hline 14 & SLVS*2/PASTOR & CIMMYT \\
\hline 15 & HAMAM-4 & ICARDA \\
\hline 16 & CHEN/AEGILOPSSQUARROSA(TAUS)//BCN/3/VEE\#7/BOW/4/PASTOR & CIMMYT \\
\hline 17 & NESTOR/3/HE1/3*CNO79//2*SERI & CIMMYT \\
\hline 18 & KOUHDASHT & IRAN \\
\hline
\end{tabular}

stressed (supplemental irrigation). The experiment in each environment was laid out in a randomized complete block design (RCBD) with four replications at Gachsaran Dryland Agricultural Research Station (Southwest of Iran) during season of 2009-2010 and 2010-2011. The size of plot was $1.05 \mathrm{~m} \times 6 \mathrm{~m}$ rows with $17.5 \mathrm{~cm}$ row spacing. All recommended agronomic practices were followed to raise good crop depend on each condition. Supplemental irrigation was carried out in two times (pollination and grain filling periods) with 30 millimeter at each time by sprinkler irrigation method in addition to 412 and 417 millimeter rainfall in the first and second years respectively which was cal model was adopted for experimental design:

$$
Y_{i j k l}=\mu+E_{i}+R(E)_{j(i)}+G_{k}+G E_{i k}+e_{i j k}
$$

where, $\mu$ : general mean; $E_{i}$ : effect of $\mathrm{i}^{\text {th }}$ environment (i $=1,2) ; R(E)_{j(i)}$ : effect of $\mathrm{j}^{\text {th }}$ block within the $\mathrm{i}^{\text {th }}$ environment $(\mathrm{j}=1,2,3) ; G_{k}$ : effect of $\mathrm{k}^{\text {th }}$ genotype $(\mathrm{I}=1,2, \ldots 10)$; $G E_{i:}$ : effect of the interaction of the $\mathrm{k}^{\text {th }}$ genotype with the $\mathrm{i}^{\text {th }}$ environment; $e_{i j k}$ : experimental Error.

Considered traits including grain yield (GY), early growth vigor (EGV), days to heading $(\mathrm{DH})$, plant height $(\mathrm{PH})$, spike length (SL), days to physiological maturity (DPM), agronomic score (AS), test weight (hectoliter) (TW), 1000 kernel weight (TKW) were studied under both conditions in every years.

\section{Statistical analysis}

The analysis of variance was conducted (year, random; rep and genotype, fixed) by Minitab (Ver 15.0) and correlation coefficients between each pairs of the traits computed by SPSS (Ver. 17.0). In path analysis, grain yield used as dependent variable, and the other studied traits were use as predictor variables. The main data collected from each water availability regime over years were separately analyzed for study relationships between grain yield and the studied traits. Path coefficient analysis was performed to occurred during crop cycle growth. The following statisti- 
divide the correlation coefficient between grain yield and the agronomic traits $\left(r_{i y}\right)$ into direct $\left(p_{i y}\right)$ and indirect effects $\left(r_{i y} p_{i y}\right)$ according the following equation:

$$
r_{i y}=p_{i y}+r_{i j} p_{i y}
$$

The technique allowed the evaluation of the direct causal effect or path coefficient $\left(\mathrm{p}_{\mathrm{iy}}\right)$ of a cause (i) on an effect (y i.e. grain yield) and indirect effect of that cause through another causal variable $(j)$. A single direct effect (unidirectional pathway) is quantitatively equal to $\mathrm{p}_{\mathrm{iy}}$ while an indirect effect is expressed as $\mathrm{p}_{\mathrm{iy}} \mathrm{r}_{\mathrm{ij}}$ of various agronomic traits on grain yield. $r_{\mathrm{ij}}$ is correlation between $\mathrm{i}$ and $\mathrm{j}$ and $r_{i y} p_{i j}$ is the indirect effect of trait i on Y via j. For example in the equation:

$$
r_{I y}=p_{I y}+r_{12} p_{2 y}, p_{I y}
$$

is the direct effect of trait 1 on response variable $(\mathrm{Y})$ (the path coefficient), while $r_{12} p_{2 y}$ is the indirect effect of trait 1 on Y via 2 (Garc1'a del Moral et al., 2003). Similar definitions apply to all of the causal effect relations.

\section{Results}

The results indicated that there were significant differences between the years for grain yield $(p=0.05)$, plant height, days to heading and spike length $(\mathrm{p}=0.01)$ under dryland condition (Tab. 2). These results also indicated year effect were significant for grain yield, days to heading, plant height, days to maturity, agronomic score and 1000 kernel weight in supplemental irrigation condition ( Tab. 3 ). There was a significant difference between wheat genotypes for grain yield under supplemental irrigation conditions, indicating genetic diversity between genotypes.

\section{Correlations}

Correlations coefficients between studied traits under two water availability conditions were presented in Tab. 4. Grain yield showed that positive and significant cor- relation with PH (0.491) and TW (0.392) under supplemental irrigation condition. The significant positive correlations were also revealed between grain yield and $\mathrm{PH}$ (0.610), SL (0.373), DPM (0.269), AS (0.257) and TW $(0.273)$ in dryland condition. The significant negative correlations were indicated between grain yield and $\mathrm{DH}$, DPM, AS, and TKW in supplemental irrigation condition and between grain yield and EGV and DH under dryland condition. Plant height revealed significant positive correlations to EGV (in supplemental irrigation condition) and SL, DPM and TW (in dryland condition). The other significant positive correlations were observed between $\mathrm{DH} /$ DPM, DH/AS, DH/TKW, SL/TKW, DPM/TKW and AS/TKW in supplemental irrigation condition. The significant positive correlations were also revealed between DH/TKW, SL/DPM, SL/AS, DPM/TKW and AS/TW in dryland condition.

\section{Path analysis}

Early growth vigor $v$ s grain yield: Early growth vigor showed positive direct effect $(0.113)$ on grain yield in supplemental irrigation condition. It has positive indirect effect through PH (0.076) while negative indirect effect via the other traits (Tab. 5). The direct effect of EGV on grain yield was negative in dryland condition $(-0.053)$. This trait had positive indirect effect on grain yield via SL and TW, but the indirect effects of EGV on grain yield were negative via the other traits (Tab. 6).

Days to heading $v s$ grain yield: Days to heading had negative direct effect $(-0.180)$ on grain yield under supplemental irrigation condition. Similar negative values were achieved from indirect effects of through PH, DPM, AS and TW; whereas, the other traits had positive indirect effects on grain yield (Tab. 5). The direct effect of $\mathrm{DH}$ was also negative on grain yield in dryland condition. The indirect effect of days to heading on grain yield by EGV

\begin{tabular}{|c|c|c|c|c|c|c|c|c|c|c|}
\hline \multirow{2}{*}{ S.O.V. } & \multirow{2}{*}{$\mathrm{df}$} & \multicolumn{9}{|c|}{ MS } \\
\hline & & GY & EGV & $\mathrm{DH}$ & $\mathrm{PH}$ & SL & DPM & AS & TKW & TW \\
\hline Year & 1 & $18998184^{*}$ & 3.21 & $4378.03^{* *}$ & $85780.6^{* *}$ & $53.57^{* *}$ & 34.02 & 0.56 & 774.69 & 711.9 \\
\hline Rep(Year) & 6 & 2668206 & 3.76 & 28.57 & 76.0 & 5.46 & 34.97 & 3.91 & 250.24 & 734.2 \\
\hline Genotype & 17 & $484842^{*}$ & 0.91 & 16.06 & $46.8^{*}$ & 1.62 & $31.43^{*}$ & $1.72^{*}$ & 15.42 & 195.2 \\
\hline $\mathrm{Y} \times \mathrm{G}$ & 17 & $287449^{* *}$ & $0.91^{* *}$ & $10.20^{* *}$ & 15.9 & 2.02 & 12.95 & 0.70 & $13.47^{* *}$ & 134.7 \\
\hline Error & 102 & 106665 & 0.43 & $1 . .57$ & 17.0 & 1.47 & 7.79 & 0.78 & 5.75 & 287.5 \\
\hline
\end{tabular}

Tab. 2. Combined analysis of variance in dryland condition

GY: grain yield; EGV: early growth vigor; DH: days to heading; PH: plant height; SL: spike length; DPM: days to physiological maturity; AS: agronomic score; agronomic score; TW: test weight (hectoliter); TKW: 1000 kernel weight; ${ }^{*}$ significant at the 0.05 probability level, ${ }^{* *}$ significant at the 0.01 probability level

\begin{tabular}{|c|c|c|c|c|c|c|c|c|c|c|}
\hline \multirow{2}{*}{ S.O.V. } & \multirow{2}{*}{$\mathrm{df}$} & \multicolumn{9}{|c|}{ MS } \\
\hline & & GY & EGV & $\mathrm{DH}$ & $\mathrm{PH}$ & $\mathrm{SL}$ & DPM & AS & TKW & $\mathrm{TW}$ \\
\hline Year & 1 & $15860081^{*}$ & 0.29 & $6916.69^{* *}$ & $4101.34^{*}$ & 2.94 & $1586.69^{* *}$ & $43.89^{* *}$ & $800.89^{* *}$ & 30.81 \\
\hline Rep(Year) & 6 & 1401647 & 1.67 & 0.94 & 473.04 & 2.33 & 8.28 & 0.44 & 46.59 & 46.38 \\
\hline Genotype & 17 & $529693^{*}$ & 0.89 & 9.89 & 64.29 & 1.18 & 19.19 & 0.34 & $21.63^{*}$ & $19.44^{*}$ \\
\hline $\mathrm{Y} \times \mathrm{G}$ & 17 & $240848^{*}$ & $0.88^{*}$ & $11.44^{* *}$ & $51.45^{*}$ & 1.25 & $32.24^{* *}$ & 0.29 & 6.88 & $8.42^{* *}$ \\
\hline Error & 102 & 138621 & 0.41 & 1.34 & 23.90 & 1.52 & 4.67 & 0.19 & 9.46 & 3.20 \\
\hline
\end{tabular}

Tab. 3. Combined analysis of variance in supplemental irrigation condition

*significant at the 0.05 probability level, ${ }^{* *}$ significant at the 0.01 probability level 
198

Tab. 4. Correlation coefficients between 7 characters measured in average of 2008-2011 in irrigated (above diagonal) and dryland condition (below diagonal)

\begin{tabular}{ccccccccccc}
\hline Traits & GY & EGV & DH & PH & SL & DPM & AS & TKW & TW \\
\hline GY & 1 & 0.128 & $-0.572^{*}$ & $0.491^{*}$ & 0.001 & $-0.478^{* *}$ & $-0.392^{* *}$ & $-0.167^{*}$ & $0.392^{*}$ \\
EGV & $-0.255^{*}$ & 1 & 0.001 & $0.227^{*}$ & -0.009 & 0.014 & 0.089 & -0.049 & -0.110 \\
DH & $-0.531^{*}$ & 0.134 & 1 & $-0.629^{*}$ & 0.108 & $0.822^{*}$ & $0.713^{*}$ & $0.528^{*}$ & $-0.201^{*}$ \\
PH & $0.610^{*}$ & $-0.185^{*}$ & $-0.907^{*}$ & 1 & -0.030 & $-0.462^{* *}$ & $-0.265^{*}$ & $-0.395^{*}$ & -0.029 \\
SL & $0.373^{*}$ & -0.109 & $-0.393^{*}$ & $0.543^{*}$ & 1 & 0.064 & 0.146 & $0.190^{*}$ & -0.008 \\
DPM & $0.269^{*}$ & -0.023 & 0.044 & $0.192^{*}$ & $0.284^{*}$ & 1 & $0.554^{*}$ & $0.399^{*}$ & $-0.213^{*}$ \\
AS & $0.257^{*}$ & -0.150 & 0.024 & 0.060 & $0.539^{* *}$ & -0.021 & 1 & $0.427^{*}$ & -0.050 \\
TKW & 0.013 & -0.125 & $0.518^{*}$ & $-0.439^{*}$ & -0.105 & $0.190^{*}$ & 0.106 & 1 & 0.139 \\
TW & $0.273^{*}$ & -0.161 & -0.106 & $0.197^{*}$ & $0.344^{*}$ & 0.043 & 0.586 & 0.046 & 1 \\
\hline
\end{tabular}

*significant at the 0.05 probability level, ${ }^{* *}$ significant at the 0.01 probability level

and $\mathrm{PH}$ were also negative in this condition. The indirect effects of $\mathrm{DH}$ on grain yield via the other traits were positive (Tab. 6).

Plant height $v$ s grain yield: Plant height showed positive direct effect on grain yield under two conditions (0.337 and 0.474 , respectively). It has also positive indirect effect through EGV, DH, DPM, AS (Tab. 5 and 6).

Spike length $v$ s grain yield: Spike length had positive $(0.045)$ and negative $(-0.239)$ direct effect on grain yield under supplemental irrigation and dryland conditions, respectively. Spike length had negative indirect effect on grain yield via the all of studied traits except of TKW in supplemental irrigation condition. Indirect effects of spike length via TKW and TW were observed showing -0.032 and -0.001 values respectively. However, the other traits had positive indirect effects in dryland condition (Tab. 6).

Days to maturity $v$ s grain yield: The direct effect of days to maturity was negative (-0.038) in supplemental irrigation condition. The indirect effects of DPM via $\mathrm{DH}$, $\mathrm{PH}, \mathrm{AS}$ and TW were also negative on grain yield; while EGV, SL and TKW had positive indirect effect on grain yield (Tab. 5). Days to maturity had positive direct effect $(0.211)$ on grain yield under dryland condition. Similar positive values were obtained from indirect effects through

Tab. 5. Path coefficients for grain yield components in supplemental irrigation condition. The diagonal under line numbers is direct effects of any trait on grain yield

\begin{tabular}{|c|c|c|c|c|c|c|c|c|c|}
\hline Traits & EGV & $\mathrm{DH}$ & $\mathrm{DH}$ & SL & DPM & AS & TKW & TW & $\begin{array}{l}\text { Overall } \\
\text { effects }\end{array}$ \\
\hline EGV & $\underline{0.113}$ & 0.001 & 0.001 & -0.001 & 0.002 & 0.010 & -0.006 & -0.012 & 0.128 \\
\hline $\mathrm{DH}$ & -0.001 & $\underline{-0.180}$ & -0.180 & -0.020 & -0.149 & -0.129 & -0.095 & 0.036 & -0.572 \\
\hline $\mathrm{PH}$ & 0.076 & -0.212 & -0.212 & -0.010 & -0.157 & -0.089 & -0.133 & -0.010 & 0.491 \\
\hline SL & -0.001 & 0.005 & 0.005 & $\underline{0.045}$ & 0.003 & 0.007 & 0.009 & -0.001 & 0.001 \\
\hline DPM & -0.001 & -0.031 & -0.031 & -0.002 & $\underline{-0.038}$ & -0.021 & -0.015 & 0.008 & -0.478 \\
\hline AS & -0.018 & -0.143 & -0.143 & -0.029 & -0.111 & $\underline{-0.201}$ & -0.086 & 0.010 & -0.392 \\
\hline TKW & -0.005 & 0.059 & 0.059 & 0.021 & 0.044 & 0.048 & $\underline{0.111}$ & 0.016 & -0.167 \\
\hline TW & -0.038 & -0.068 & -0.068 & -0.002 & -0.073 & -0.016 & 0.048 & $\underline{0.345}$ & 0.390 \\
\hline \multicolumn{6}{|c|}{$\mathrm{R}^{2}=0.47$} & \multicolumn{4}{|c|}{$\sqrt{1-R^{2}}=0.71$} \\
\hline
\end{tabular}

Tab. 6. Path coefficients for grain yield components in dryland condition. The diagonal under line numbers is direct effects of any trait on grain yield

\begin{tabular}{|c|c|c|c|c|c|c|c|c|c|}
\hline Traits & EGV & $\mathrm{DH}$ & $\mathrm{DH}$ & SL & DPM & AS & TKW & TW & $\begin{array}{l}\text { Overall } \\
\text { effects }\end{array}$ \\
\hline EGV & $\underline{-0.053}$ & -0.007 & 0.010 & 0.006 & 0.001 & 0.008 & 0.007 & 0.009 & -0.255 \\
\hline $\mathrm{DH}$ & -0.049 & $\underline{-0.362}$ & 0.328 & 0.142 & -0.016 & -0.009 & -0.187 & 0.038 & -0.531 \\
\hline $\mathrm{PH}$ & -0.087 & -0.430 & $\underline{0.474}$ & 0.258 & 0.091 & 0.029 & -0.208 & 0.093 & 0.610 \\
\hline SL & 0.026 & 0.094 & -0.130 & -0.239 & -0.068 & -0.129 & 0.025 & -0.082 & 0.373 \\
\hline DPM & -0.005 & 0.009 & 0.040 & 0.060 & $\underline{0.211}$ & -0.004 & 0.040 & 0.009 & 0.269 \\
\hline AS & -0.050 & 0.008 & 0.020 & 0.180 & -0.007 & $\underline{0.333}$ & 0.035 & 0.195 & 0.257 \\
\hline TKW & -0.038 & 0.156 & -0.132 & -0.032 & 0.057 & 0.032 & $\underline{0.301}$ & 0.014 & 0.013 \\
\hline TW & 0.001 & 0.001 & -0.001 & -0.001 & -0.001 & -0.002 & -0.001 & $\underline{-0.004}$ & 0.272 \\
\hline \multicolumn{6}{|c|}{$\mathrm{R}^{2}=0.52$} & \multicolumn{4}{|c|}{$\sqrt{1-R^{2}}=0.67$} \\
\hline
\end{tabular}


EGV, PH and TKW; whereas, DH, SL, AS and TW had negative indirect effects on grain yield (Tab. 6).

Agronomic score $v$ s grain yield: Agronomic score had negative direct effect on grain yield in supplemental irrigation condition. The indirect effects of DH, PH, DPM and TW were also negative on response variable (Tab. 5). Agronomic score had positive direct affect $(0.333)$ on grain yield in dryland condition. Similar positive values were obtained from the indirect effects by EGV, PH and TKW. Agronomic score had negative indirect effect on grain yield via DH, SL, DPM and TW (Tab. 6).

Thousand kernel weight $v$ s grain yield: Positive direct effects of 1000 kernel weight on grain yield were indicated in both environments. The positive indirect effect of TKW on grain yield via SL and TW were indicated in supplemental irrigation condition (Tab. 5); whereas the positive indirect effects of TKW on grain yield revealed by EGV, SL, DPM and AS in dryland condition (Tab. 6). The indirect effects of TKW on grain yield via the other traits were negative in two conditions.

Test weight (hectoliter) $v$ s grain yield: Test weight had positive direct effect $(0.345)$ on grain yield under supplemental irrigation condition (Tab. 5). The indirect effects of TW on grain yield were positive through DH, DPM, AS and TKW, while indirect effects of TW through the other traits were negative in this condition. The direct effect of TW on grain yield and its indirect effect via SL were negative in dryland condition, but the indirect effects of TW via the other traits were negative in this situation (Tab. 6).

\section{Discussions}

In this research, the positive and significant correlation was observed between grain yield and plant height and test weight (hectoliter) under supplemental irrigation condition. The grain yield, a major selection criterion versus drought stress, is a complex trait that determined by several physiological, biochemical and metabolic plant processes and its genetics and associations are greatly ambiguous (Ali et al., 2011). The traits such as plant height, spike length, days to heading, AS and test weight (hectoliter) had significant and positive correlation coefficients with grain yield in dryland condition, indicating its importance for selection with drought tolerance and higher yields. This finding is in agreement with the findings of Leilah and Al-Khateeb (2005). Dogan (2009) also indicated positive and significant correlations between grain yield and test weight. Dagustu (2008) indicated significant and positive correlations between grain yield and spike length. According to the results of correlation coefficients, suggesting to increase grain yield under dryland condition, the more focus should be on morphological traits such as plant height and spike length which have a high correlation with grain yield and also should utilize them in drought resistance breeding programs.
Path coefficient analysis revealed that grain yield of bread wheat in dryland condition depended on the effect of plant height, days to maturity, agronomic score and 1000 kernel weight, whereas in supplemental irrigation condition was mainly related to plant height, spike length, 1000 kernel weight and test weight. This result was in agreement with the report of Aydin et al. (2010) that indicated plant height had the greatest direct effect on grain yield and suggested that plant height and test weight are primary selection criteria for improving grain yield in wheat in high and low rainfall conditions. This result was also similar to research of Ahmadizadeh et al. (2011) that showed spike length had more direct positive effects on grain yield. Sen and Toms (2007) also revealed that 1000 weight showed a direct effect on wheat grain yield. Gulmezoglu et al. (2010) revealed that grain yield of wheat depended on plant height, length of spike and spike weight. Shamsi et al. (2011) also showed that the most important yield component on grain yield was 1000 grain weight. The influence of 1000 kernel weight on grain yield in two irrigation conditions seems to cause from the fact that grains yield in wheat is frequently the sink limited (Fischer, 1985), and for this reason, the 1000 kernel weight has been reported as a promising trait in increasing grain yield in wheat in irrigated and dryland conditions. The potential wheat grain yields at filling stage are dependent to limitation of sink and enlarging sink capacity can be caused grain yield increasing.

The direct effect of 1000 kernel weight on grain yield was positive under supplemental irrigation condition, while the correlation coefficient between these two traits was negative. This is resulting from negative indirect effects of TKW on grain yield via EGV, DH, PH, DPM and AS. The correlation coefficient between grain yield and PH and TW (in irrigated) and PH, DPM and AS (in dryland) is nearly equal to its direct effect. Singh and Chaudhary (1979) suggested that if the correlation coefficient between a causal factor and the effect is almost equal to its direct effect, then correlation explains the true relationship and direct selection through this trait will be effective. Therefore, these traits could be used as selection criteria for improving wheat grain yield in two conditions. In the other hand, plant height had positively and directly influenced grain yield, in two conditions and suggesting a criteria trait for improving of grain yield under irrigated and dryland situation. The results showed that genotype 12 (CS/TH.SC//3*PVN/3/MIRLO/BUC/4/ MILAN/5/TILHI) is high yielding potential genotype in moisture limited conditions, and related with low plant height (63.73), intermediate days to maturity (123) and agronomic score (3.81). Correlation analysis was separately estimated for this genotype and indicated high correlation coefficient between grain yield and days to maturity $(0.70)$ and agronomic score $(0.74)$ (the data were not shown). The direct effect of spike length on grain yield was negative in dryland condition and positive in supplemen- 
200

tal irrigation condition. The comparison of these results revealed that stress condition leads to less balance between the sink and the source.

\section{Conclusions}

The results of correlation and path analysis in this work revealed nearly parallel results for interrelationships among various traits. Correlation and path analysis concluded that plant height, spike length and test weight could be the reliable and potential selection criteria among the yield related traits in supplemental irrigation condition, while plant height, days to maturity, agronomic score and 1000 kernel weight under dryland condition could be reliable morpho-physiological traits for drought tolerance and obtaining a high potential yielding in dryland condition. Breeding to increase the potential yield of wheat crops in water limited condition is influenced by $\mathrm{PH}, \mathrm{DPM}, \mathrm{AS}$ and TKW and could be used genotype 12(CS/TH.SC// 3*PVN/3/MIRLO/BUC/4/MILAN/5/TILHI) as a breeding material for increasing grain yield in drought condition.

\section{References}

Ali MA, Abbas A, Awan SI, Jabran K, Gardezi SDA (2011). Correlated response of various morpho-physiological characters with grain yield in sorghum landraces at different growth phases. J Animal Plant Sci 21(4):671-679.

Ahmadizadeh M, Shahbazi H, Valizadeh M, Zaefizadeh M (2011). Genetic diversity of durum wheat landraces using multivariate analysis under normal irrigation and drought stress conditions. Afric J Agric Res 6(10):2294-2302.

Aydin N, Ermet C, Mut Z, Bayram HO, Özcan H (2010). Path analyses of yield and some agronomic and quality traits of bread wheat (Triticum aestivum L.) under different environments. Afric J Bio 9(32):5131-5134.

Blum A (2011).Plant Breedingfor Water-LimitedEnvironments. Springer New York Dordrecht Heidelberg London.

Dagustu N (2008). Genetic analysis of grain yield per spike and some agronomic traits in diallel crosses of bread wheat (Triticum aestivum L.). Turk J Agric For 32:249-258.

Dogan R (2009). The Correlation and path analysis for yield and some of yield components of durum wheat (Triticum turgidum var. durum) in west Anatolia conditions. Pak J Bot 41(3):1081-1089.

Fischer RA (1985). Number of kernels in wheat crops and the influence of solar radiation and temperature. J Agric Sci 105:447-461.

Ghaderi MG, Zeinalikhanghah H, Hosseinzadeh AH, Taleei AR, Naghavi MR (2009). Evaluation of relationships between grain yield, yield components and the other characteristics associated with grain yield in bread wheat using multivariate statistical analysis. Iran J crop Res 7(2):573-582 (In Persian).
Garci'a del Moral LF, Rharrabti Y, Villegas D, Royo C (2003). Evaluation of grain yield and its components in durum wheat under Mediterranean conditions: an ontogenic approach. Agron J 95:266-274.

Gulmezoglu N, Alpu O, Ozer E (2010). Comparative performance of triticale and wheat grains by path analysis. Bulgar J Agric Sci 16 (4):443-453.

Kandic V, Dodig D, Jovic M, Nikolic B, Prodanovic S (2009). The importance of physiological traits in wheat breeding under irrigation and drought stress. Genetika 41(1):11-20.

Khan AJ, Azam F, Ali A (2010). Relationship of morphological traits and grain yield in recombination inbred with lines grown under drought conditions. Pak J Bot 42(1):259-267.

Khayatneghad M, Zaefizadeh M, Gholamin R, Jamaati-eSomarein SH (2010). Study of genetic diversity and path analysis for yield in durum wheat genotypes under water and dry conditions. World Appl Sci J 9(6):655-665.

Leilah AA, Al-Khateeb SA (2005). Statistical analysis of wheat yield under drought conditions. J Arid Env 61:483-496.

Mollasadeghi V, Imani AA, Shahryari R, Khayatnezhad M (2011). Correlation and path analysis of morphological traits in different wheat genotypes under end drought stress condition. Mid-East J Sci Res 7(2):221-224.

Shamsi K, Petrosyan M, Noor-mohammadi G, Haghparast A, Kobraee S, Rasekhi B (2011). Differential agronomic responses of bread wheat cultivars to drought stress in the west of Iran. Afric J Bio 10(14):2708-2715.

Sen C, Toms B (2007). Character association and component analysis in wheat (Triticum aestivum L.). Crop Res (Hisar) 34:166-170.

Singh RK, Chaudhary BD (1979). Boimetrical methods in quantitative genetic analysis, Kalyani Publisher Ludhiana, $304 \mathrm{p}$.

Taheri S, Jalal S, Shekari F, TL Abdullah (2011). Effects of drought stress condition on the yield of spring wheat (Triticum aestivum) lines. Afric J Bio 10(80):18339-18348.

Zakizadeh M, Esmaeilzadeh M, Kahrizi D (2010). Study on genetic variation and relationship between plant characteristics and grain yield in long spike bread wheat (Triticum aestivum L.) genotypes-using multivariate analysis. Iran J Crop Sci 12(2):18-30 (in Persian).

Zhou XB, Chen YH (2011). Yield response of winter wheat to row spacing under irrigated and rainfed conditions. Bulg J Agric Sci 17:158-166.

Zhou XB, Chen YH, Ouyang Z (2011). Row spacing effects on soil water and water consumption of winter wheat under irrigated and rainfed conditions. Plant Soil Environ 57(3):115-121. 